Chapter 8

\title{
Well-being and Quality of Life-Medical Perspective
}

\author{
Nkporbu A.K.
}

Additional information is available at the end of the chapter

http://dx.doi.org/10.5772/intechopen.68730

\begin{abstract}
The prevalence of chronic diseases, both communicable and non communicable, has continued to increase worldwide and its consequences including psychiatric co-morbidity with accompanying decrease in quality of life of the sufferers. The aim of this study, therefore, was to determine the quality of life of patients with HIV, Tuberculosis, Diabetes Mellitus and Hypertension and the effect of psychiatric comorbidity on the quality of life and well-being of these patients who attend the different out-patient clinics of the University of Port Harcourt Teaching Hospital( UPTH). Following ethical approval and informed consent from the participants, 120 subjects from each group of HIV, Tuberculosis, Diabetes Mellitus and Hypertension were recruited based on the study's inclusion and exclusion criteria. Subjects were further administered with the study's instruments including the socio-demographic/clinical questionnaire, GHQ-12, WHO Composite International Diagnostic Interview (WHO CIDI) and the WHO QOL-Bref. The data were analyzed using the Statistical Package for Social Sciences (SPSS) version 20 statistical package. Confidence interval was set at $95 \%$ while P-value of less than 0.05 was considered statistically significant. The study found a prevalence of psychiatric comorbidity of $43.75 \%$ in all. Tuberculosis had the highest prevalence of psychiatric comorbidity with $63(52.5 \%)$, followed by . hypertension with $59(49.17 \%)$, and Diabetes mellitus $46(38.3 \%)$, while HIV was the least with $42(35 \%)$. There were significant relationships between the presence of psychiatric co-morbidity and level of education $(\mathrm{p}=0.004)$, income class $(\mathrm{p}=0.001)$ in all four medical conditions and self stigma for HIV and tuberculosis. Hypertension had the highest average mean quality of life with $6.34+253$ followed by HIV with 60. , diabetes with 5.8 while tuberculosis had the least with mean quality of life $5.3(\mathrm{p}=0.001)$. However, when quality of life was associated with psychiatric comorbidity, the mean quality of life was 5.9, 5.6, 5.2 and 4.9 for Hypertension, diabetes, HIV and tuberculosis respectively. The management of patients with these medical conditions should therefore necessarily include adequate attention to the mental health status the sufferers.
\end{abstract}

Keywords: Chronic medical diseases, Psychiatric Co-morbidity, QOL, Well-being, UPTH 


\section{Introduction}

The prevalence of chronic medical diseases, both communicable including HIV [1] and tuberculosis infections [2] and non-communicable including diabetes mellitus [3] and hypertension [4], has continued to increase worldwide with a corresponding increase in the awareness of their possible comorbidities. These four medical conditions are among the most common chronic conditions in Sub-Saharan Africa and indeed worldwide [3, 5]. Psychiatric comorbidities have been identified as one of the commonest groups of comorbidities associated with chronic medical conditions [6-8]. Knowledge of psychiatric comorbidities particularly in these four chronic medical conditions has increased tremendously over the past decades and their effects on chronic disease outcome particularly quality of life and well-being have remained a growing concern $[9,10]$. Even in the presence of all these findings, there is still low level of awareness of the psychological effects of these medical diseases particularly among clinicians who are non-psychiatrists. This often leads to poor management of patients, high morbidity, mortality and poor prognostic outcome.

In 2010, it was reported that diabetes mellitus affected about 285 million adults (age 20-79 years) worldwide and this figure may increase to about 439 million adults by 2030 [3]. Similarly, tuberculosis is reported as one of the leading causes of mortality worldwide [12], with the World Health Organization (WHO) estimation of about two billion people, having latent tuberculosis. This number of persons makes up almost a third of the world's population $[5,11]$. Every year about eight million people develop this disease, and some three million die of it, with more than $95 \%$ of these from developing countries [13]. A study [14] estimates a prevalence of between 10 and $15 \%$ of adult populations worldwide to have high blood pressure which also agrees with similar report in Africa [15]. But this is different from other studies which reported a prevalence of $15-30 \%$ in adults worldwide [16]. Five key factors have been identified to be associated with hypertension in the Western world: increasing age, obesity, elevated pressure in blood relative, environment and race [17]. Furthermore, over 36 million people have contracted HIV infection worldwide and about 16 million people are said to have died from the disease [1,7]. In the 1960s and 1970s, HIV-related disorders and AIDS were increasingly common but unrecognized, particularly in Africa and North America. In Nigeria, the following prevalence rates have been reported for the four medical conditions: about $10-15 \%$ for diabetes mellitus [4] and about $4.6 \%$ for HIV infection [1], $10-15 \%$ for essential hypertension [14], and increasing from $11.2 \%$ in 1990 to $27.9 \%$ in 2010 in rural communities in the Niger Delta, and $44.3 \%$ in urban Lagos $[18,19]$ while tuberculosis is $36-45 \%$ [20].

Although these four medical conditions may appear dissimilar, within them lie some comparative similarities. Diabetes mellitus and hypertension have genetic component, adverse environmental factors, and prevalent life style as major risk factors [21-24], while HIV and tuberculosis are both chronic infectious diseases and are mainly acquired from infected objects or persons $[25,26]$. In fact, a strong genetic association between diabetes mellitus and depression has been reported [27, 24]. Also, HIV and tuberculosis infections, unlike diabetes and hypertension, are associated with high level of stigmatization and social discrimination 
$[28,29]$. These diseases have similar complications which include among others diabetic ketoacidosis, HIV and hypertensive encephalopathies, and CNS disseminated tuberculosis which may affect all the brain cells, leading to altered sensorium, neuro-affections, neurodeficits, cognitive impairment, organic mental syndrome and in some individuals seizures may occur. Similarly, all four illnesses could directly impair important neurotransmitter functions due to their direct toxic effects on the brain cells (neurons) either from the viral cells [30] or other opportunistic infections [31], disseminated tuberculosis to the CNS, hypertensive encephalopathy or due to ketoacidotic complication. All these are capable of disrupting the neurotransmitter system and this may affect the limbic system, the center that regulates mood in humans.

\section{Chronic medical conditions and psychiatric comorbidity}

Chronic medical diseases, besides being associated with high rate of mortality, are equally associated with various forms of comorbidities and psychiatric comorbidity appears to be most common and most disabling [31-37]. It has been reported that about $20 \%$ of patients with somatic diseases suffer from major depression [38]. Strong causal associations have equally been found to exist between mental disorders especially depression, anxiety and hypertension and diabetes $[39,40]$. Besides the genetic components, persistent environmental stressors are also well-known triggers for hypertension and diabetes mellitus [23]. They rearrange and over intensify the sympathetic system [42] by initiating or enhancing the release of norepinephrine which stimulates the sympathetic pathway. Thus, this neurotransmitter is consequently hyperactivated and becomes oversensitized in most chronic diseases. This causes both hypertension and anxiety disorders including panic disorder, General Anxiety Disorder (GAD), acute stress disorder and posttraumatic stress disorder (PTSD) [43-45]. Also, most of the psychotropic drugs have been known to be diabetogenic either by slowing down body metabolism including carbohydrates and or causing increased appetite. Again, a genetically causal link has been established between depression and diabetes with abnormal chromosome 21 being implicated. Additionally, the presence of anxiety alone could lead to hypertension and diabetes mellitus in predisposed individuals $[39,40]$.

Infectious chronic medical diseases like HIV and tuberculosis equally create multiple burdens for patients, including the need to deal with pain, suffering, reduced quality of life, poor compliance to medication, premature mortality, financial costs, stigma, discrimination, isolation, rejection and familial emotional trauma [46]. The co-existence of psychiatric disorders with various communicable and non-communicable diseases (NCDs) is a relevant phenomenon, which tend to be chronic in nature and has significant implications in the patient's well-being, quality of life, cost of treatment as well as longevity of the patient. Other available evidence have clearly showed an increasing prevalence of psychiatric comorbidities among communicable and NCD patients [32-34, 47,48]. The chronic nature of these medical illnesses, their persistent and recurrent symptoms, impairment in functioning capacity, as well as other adverse environmental psycho-social burdens and even the worried thought of these can also in turn cause anxiety and may also quickly drive the patient into depression, 
suicidal ideation or attempt, and ultimately suicide. It is therefore important to note that the adverse environmental factors could lead to both the medical conditions and mental illness and can equally aggravate them. Although HIV- and tuberculosis-infected patients under anti-retroviral (arbacire and niverapine) and anti-tuberculosis drugs (isoniazid, ethambutol and cycloserine) therapy infrequently suffer acute organic psychotic complications [49-52], the chronicity of the disease places them at greater risk for psychiatric comorbidity than the general population [53]. Acute episodes of mania or manic phase of bipolar affective disorder tend to occur in HIV and tuberculosis patients [54, 55].

In addition to the effect of psychiatric comorbidity on quality of life in patients with chronic diseases, depression also contributes to poor self-care, reduced immunity, poor adherence to medical treatment, higher rates of medical morbidity and mortality and increased health-care costs $[56,57]$. The enduring thought of the prolong illness, and the tendency for long-term treatment including the inconvenience of routine or daily parenteral or oral medication, the functional incapacitation, the burden of care including financial, the stigma (both externalized and internalized) and the social rejection are more than enough psycho-social factors to impact mental ill health. In addition to these, the presence of depressive symptoms is also related to hypertensive and diabetes self-care, reflected by a worse adherence to medications, diet and exercise advice including reduction on alcohol use [58,59]. The available studies suggest that psychiatric comorbidity particularly depression may indeed precede a decrease in quality of life among patients suffering from chronic medical illness [60]. However, the possibility of reversed causality, for example, that a reduced quality of life or physical function in individuals with chronic diseases preceding the development of depressive symptoms cannot be ruled out. Chronic diseases, psychiatric comorbidity particularly depression and anxiety and quality of life are closely related triad. The causality and time course and path of these relations remain largely unknown. There is therefore need for an integrated chronic disease care approach that addresses both the practical and emotional issues.

It is also worthy of note that while some medications that are used in the treatment of these medical conditions are associated with neuropsychiatric side effects like channel blockers and propranolol for hypertension, strong association has also been found between some medications used in the treatment of some mental disorders and diabetes mellitus (Selective Serotonin Reuptake Inhibitor (SSRI) and Olanzepine) and hypertension (TCA). Mental disorders can equally predispose individuals to hypertension or diabetes [39-41], and also to acquiring HIV and or tuberculosis due to poor sense of judgment, leading to sexual indiscretion and other risk bearing practices [61]. In addition, the mentally ill are often taken advantage off and subjected to sexual assaults, which is one of the major modes of transmission of HIV infection. Furthermore, some medications have been known to be immunosuppresants in their action and by so doing can increase the vulnerability of individuals to these infections. Additionally, use of alcohol and other drugs of abuse, which is common in most chronic diseases, makes them vulnerable to enter casual or coercive sexual relationship [62-64]. Mental disorders particularly depression can lower immunity thereby making the individuals vulnerable to these infectious diseases. 


\section{Quality of life and well-being in patients with chronic medical conditions}

The terms 'quality of life' and, more specifically, 'health-related quality of life' refers to the physical, psychological and social domains of health, seen as distinct areas that are influenced by a person's experiences, beliefs, expectations and perception $[65,66]$, ('which is referred here collectively as perceptions of health'). The emphasis within the above definition is first, on the subjective nature of QOL and second, on the need to assess all those aspects of life considered as having significant impact on QOL and well-being of any individual. Quality of life assessment is aimed at measuring changes in physical, functional, mental and social health of the individual and then the population in order to evaluate the human and financial cost and benefits of new programs and interventions $[65,66]$.

'Quality of life' is characterized by an individual's awareness on his ability to function well, cope with his or her daily demands and be in good health socially, physically and mentally [67]. A self-reporting questionnaire which is reliable and has valid numbers can use to measure one's quality of life. This questionnaire is categorized in three main groups: generic, disease and domain specifications [68]. The generic specification measures patients' quality of life irrespective of the presence of any diseases. The disease specification deals with the consequences, cost and depth of a specific disease on the patients' quality of life. While the final domain specified on certain domains in patients' quality of life, for example, if there are any physical inabilities.

Quality of life therefore is affected in a complex way by the individual's physical health, psychological state, as well as their sense of independence, level of social relationships, personal beliefs and their other relationships to salient features of their environment. Quality of life also consists of fulfilling needs, meeting of social expectations and assessing opportunities by using abilities. Abilities are impaired by ill health and worse still chronic medical illnesses [68-70]. Quality of life can be altered by both the immediate and the long-term consequences of treatment especially the case of chronic illnesses [71-78]. Hence, the focus of medical practice has always been directed toward relieving physical symptoms of chronic medical diseases which often overlook the huge impact on the physical and psychological well-being, psychiatric comorbidity and the overall patient's quality of life. This has often resulted in monumental adverse health outcomes [79-81]. Also, emphasis is usually on treating the basic abnormality and most times symptomatology of the disease leaving the individuals' own views of their state of well-being.

Most chronic medical conditions weaken patients' physical functioning and impair their quality of life $[82,83]$. It has become important that tuberculosis and HIV control programs at public health clinics design strategies to improve the quality of health of tuberculosis and HIV separately or co-infected patients. Tuberculosis affected all predicted domains of QOL, including general health perceptions, somatic sensation, psychological health, spiritual wellbeing, and physical, social and role functioning [74-76]. Social stigmatization, isolation, pill burden, long duration of therapy, sexual dysfunction, loss of income and fear are associated with chronic medical diseases and all affect patients' QOL and well-being. Despite available 
curative therapy, chronic diseases and their treatment still have significant short- and longterm consequences on patients' QOL [69, 73, 75].

Several factors are known to influence both depressive symptoms and quality of life, including age, sex, marital status, educational level or income $[77,81]$. These factors may confound the association between depressive symptoms and quality of life. Depressive symptoms in individuals with chronic medical diseases are associated with a worse quality of life [84-88]. Generic, disease specific, as well as domain specific quality of life are poorer in the presence of depressive symptoms [89]. In addition, there is evidence that depressive symptoms can predict the development of functional limitations in the future, suggesting a causal relationship between depressive symptoms and functional disability [90].

\section{Aim}

The aim of this study, therefore, was to determine the quality of life of patients with chronic medical diseases: HIV, tuberculosis, diabetes mellitus and hypertension and the effect of psychiatric comorbidity on the quality of life and well-being of these patients who attend the different out-patient clinics of the University of Port Harcourt Teaching Hospital (UPTH).

\section{Methodology}

Following ethical approval and informed consent from the participants, 120 subjects from each group of HIV, tuberculosis, diabetes mellitus and hypertension were recruited based on the study's inclusion and exclusion criteria. Patients with additional medical condition including having two of the four illnesses under consideration, severely ill patients, for example, with evident AIDS and multi-drug resistant tuberculosis were excluded. Age range of 10-70 years was a criterion. A pilot study was carried out. Subjects were further administered with the study's instruments including the socio-demographic/clinical questionnaire, GHQ-12, WHO composite international diagnostic interview (WHO CIDI) and the WHOQOL-Bref. The data were analyzed using the SPSS version 20 statistical package. Confidence interval was set at $95 \%$ while $P$ value of less than 0.05 was considered statistically significant.

\subsection{WHO QOL-Bref}

The World Health Organization quality of life assessment instrument, short version (WHOQOL-Bref, used in this study) is a 26-item questionnaire that assesses how patients feel about their life $[91,92]$.The WHOQOL produces a quality of life profile with four domain scores and general health facet. The four domain scores and general health facet test an individual's perception of quality of life in each particular domain. Scores on domain 1 assess 
physical health; domain 2 psychological health; domain 3 social relationship and domain 4 assess individual's perception of the environment. Domain scores are scaled in a positive direction (higher score denotes higher quality of life) [91, 92]. QOL represents the effect of an illness on a patient, as perceived by the patient, and yields complementary information to medical or epidemiological data, and it is often used as an outcomes measurement [93]. QOL has also been characterized as 'the ultimate goal of all health interventions'.

\subsection{The general health questionnaire (GHQ-12)}

It is a self-administered screening instrument, which was designed to detect short-term changes in mental health (anxiety, depression, somatic symptoms and social dysfunctions) and to screen for psychiatric morbidity [94-96]. It is aimed at distinguishing between psychological ill health and well-being. It can detect disorders of less than two-week duration. It focuses on breaks in normal functioning and is concerned with a person's inability to continue with normal healthy functions and the experience of new phenomena of a distressing nature.

\section{Results}

\subsection{Psychiatry diagnosis}

From the study, tuberculosis had the highest prevalence of psychiatric comorbidity with 63 (52.5\%), followed by hypertension with 59 (49.17\%), and diabetes mellitus 46 (38.3\%), while HIV was the least with 42 (35\%). Depression was the most common psychiatric disorder among all the medical conditions with 11.67, 15.83, 9.16 and 15\% among diabetes, hypertension, HIV and tuberculosis, respectively, followed by generalized anxiety disorder. In a total of 12 patients ( 5 among the HIV and 7 among the tuberculosis) had psychosis, 2 and 3 cases which occurred following commencement of anti-retroviral and anti-tuberculosis medications, respectively (see Table 1).

\begin{tabular}{|c|c|c|c|c|c|}
\hline \multirow[t]{2}{*}{$\mathrm{S} / \mathrm{N}$} & \multirow[t]{2}{*}{$\begin{array}{l}\text { Psychiatric } \\
\text { morbidity total }\end{array}$} & \multirow{2}{*}{$\begin{array}{l}\text { Diabetes mellitus } \\
(\%) \\
\mathrm{n}=120\end{array}$} & \multirow{2}{*}{$\begin{array}{l}\text { Hypertension (\%) } \\
\mathrm{n}=120\end{array}$} & \multirow{2}{*}{$\begin{array}{l}\text { PLWHV (\%) } \\
\mathrm{n}=120\end{array}$} & \multirow{2}{*}{$\begin{array}{l}\text { Tuberculosis }(\%) \\
\mathrm{n}=120\end{array}$} \\
\hline & & & & & \\
\hline 1 & $\begin{array}{l}\text { Depressive } \\
\text { disorders (with } \\
\text { or without } \\
\text { psychosis) }\end{array}$ & 14 (11.67) & $19(15.83)$ & $11(9.16)$ & $18(15.0)$ \\
\hline 2 & GAD & $8(6.06)$ & $10(8.33)$ & 7 (5.83) & $11(9.16)$ \\
\hline 3 & $\begin{array}{l}\text { Sexual } \\
\text { dysfunctions }\end{array}$ & $2(1.66)$ & $5(4.16)$ & $2(1.66)$ & 2 (1.66) \\
\hline 4 & $\begin{array}{l}\text { Mixed anxiety } \\
\text { and depressive } \\
\text { disorders }\end{array}$ & $6(5.0)$ & $8(6.66)$ & $4(3.33)$ & $7(5.83)$ \\
\hline
\end{tabular}




\begin{tabular}{|c|c|c|c|c|c|}
\hline \multirow[t]{2}{*}{$\mathrm{S} / \mathrm{N}$} & \multirow[t]{2}{*}{$\begin{array}{l}\text { Psychiatric } \\
\text { morbidity total }\end{array}$} & \multirow{2}{*}{$\begin{array}{l}\text { Diabetes mellitus } \\
(\%) \\
n=120\end{array}$} & \multirow{2}{*}{$\begin{array}{l}\text { Hypertension (\%) } \\
\mathrm{n}=120\end{array}$} & \multirow{2}{*}{$\begin{array}{l}\text { PLWHV (\%) } \\
\mathrm{n}=120\end{array}$} & \multirow{2}{*}{$\begin{array}{l}\text { Tuberculosis }(\%) \\
\mathrm{n}=120\end{array}$} \\
\hline & & & & & \\
\hline 5 & Substance abuse & $3(2.5)$ & $5(4.16)$ & $3(2.5)$ & $5(5.83)$ \\
\hline 6 & $\begin{array}{l}\text { Adjustment } \\
\text { disorder }\end{array}$ & $2(1.66)$ & $1(0.83)$ & $2(1.66)$ & $1(0.83)$ \\
\hline 7 & PSTD & $0(0)$ & $0(0)$ & $3(2.5)$ & $3(2.5)$ \\
\hline 8 & $\begin{array}{l}\text { Panic without } \\
\text { agoraphobia }\end{array}$ & $0(0)$ & $0(0)$ & $1(0.83)$ & $1(0.83)$ \\
\hline 9 & Dysthymia & $3(2.5)$ & $4(3.33)$ & $2(1.66)$ & $3(2.5)$ \\
\hline 10 & $\begin{array}{l}\text { Phantom } \\
\text { disorders }\end{array}$ & $2(1.66)$ & 0 & $0(0)$ & $0(0)$ \\
\hline 11 & Social phobia & $2(1.66)$ & $3(2.5)$ & $2(1.66)$ & $2(1.66)$ \\
\hline 12 & Somatization & $4(3.33)$ & $3(2.5)$ & $3(2.5)$ & $5(4.16)$ \\
\hline 13 & $\begin{array}{l}\text { Personality } \\
\text { disorders }\end{array}$ & $0(0)$ & $1(0.83)$ & $1(0.83)$ & $2(1.66)$ \\
\hline 14 & BAD & $0(0)$ & 00 & $1(0.83)$ & $3(2.5)$ \\
\hline 15 & $\begin{array}{l}\text { Nil (No } \\
\text { psychiatric) } \\
\text { illness) }\end{array}$ & $74(62.0)$ & $61(51.0)$ & $78(65.0)$ & $57(47.5)$ \\
\hline
\end{tabular}

Note: Percentages reflect proportions within each medical conditions.

Table 1. Psychiatric comorbidity among diabetes.

\subsection{Socio-demographic and clinical correlates of psychiatric morbidity}

In all four medical conditions, there was no significant relationship between the presence of psychiatric comorbidity and age class $(P=0.350)$, gender $(P=0.22)$, level of education $(P=043)$, income class $(P=0.81)$ and occupation. Persons who were married were significantly more likely to have a psychiatric comorbidity $(P<0.001)$. Also, those who reacted with either 'very sad' or a 'wish to die' when they received the diagnosis of the medical conditions were more likely to have psychiatric comorbidity $(P=0.001)$. There was also no significant relationship between age of onset of illness $(P=0.60)$, duration of illness $(P=0.73)$, duration of treatment $(P=0.82)$ and self-stigma $(P=0.15)$ (see Table 2$)$.

\subsection{Association of psychiatric comorbidity with quality of life among patients with diabetes mellitus, hypertension, HIV and tuberculosis}

On domains 1 and 4, PLWHIV who had psychiatric comorbidity had better performance on quality of life, followed by hypertension, diabetes mellitus while tuberculosis had the least in similar domains. Furthermore, PLWHIV free of psychopathology also scored higher on general health facet (GHF) than similar group among the other three medical conditions (see Table 3). 


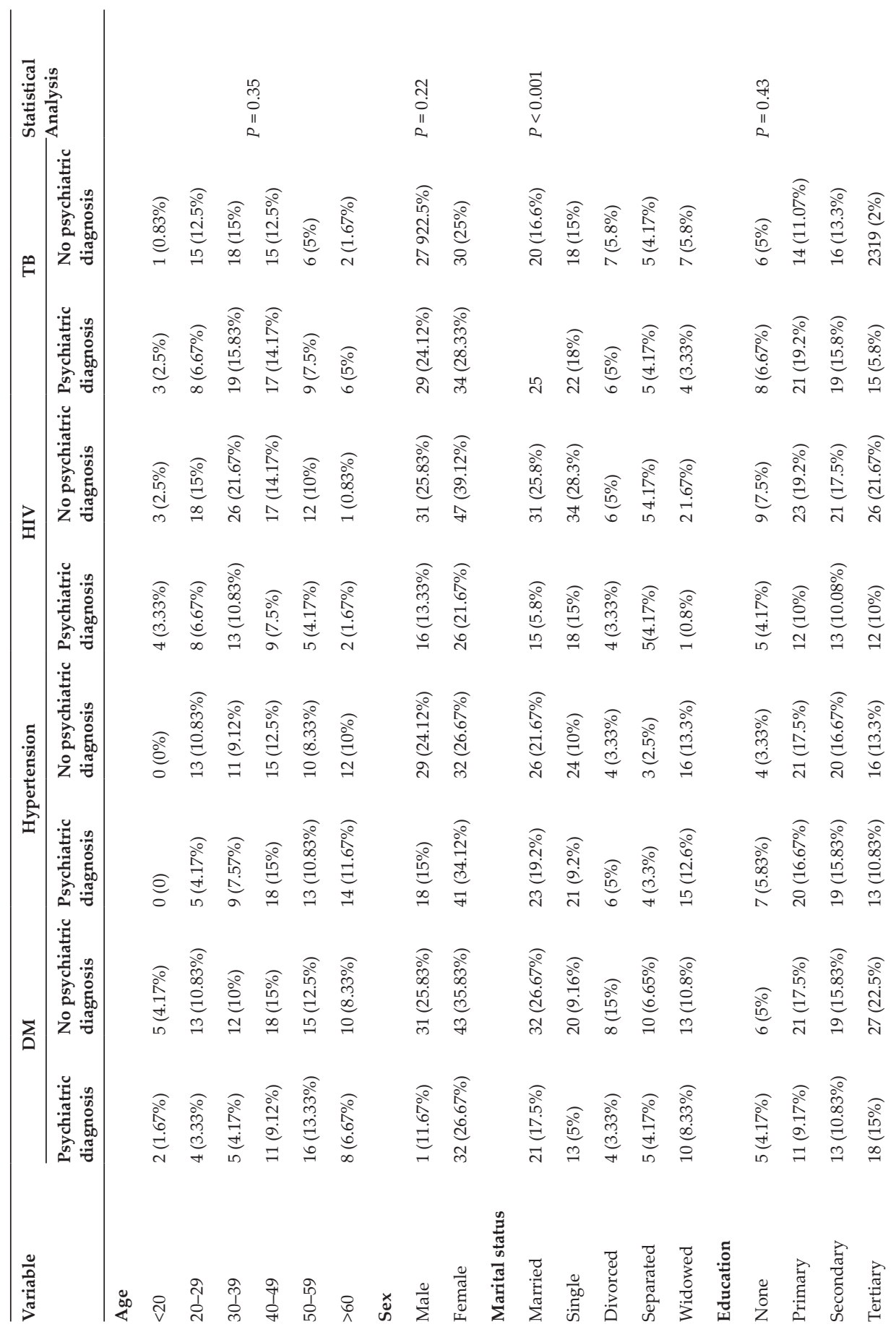




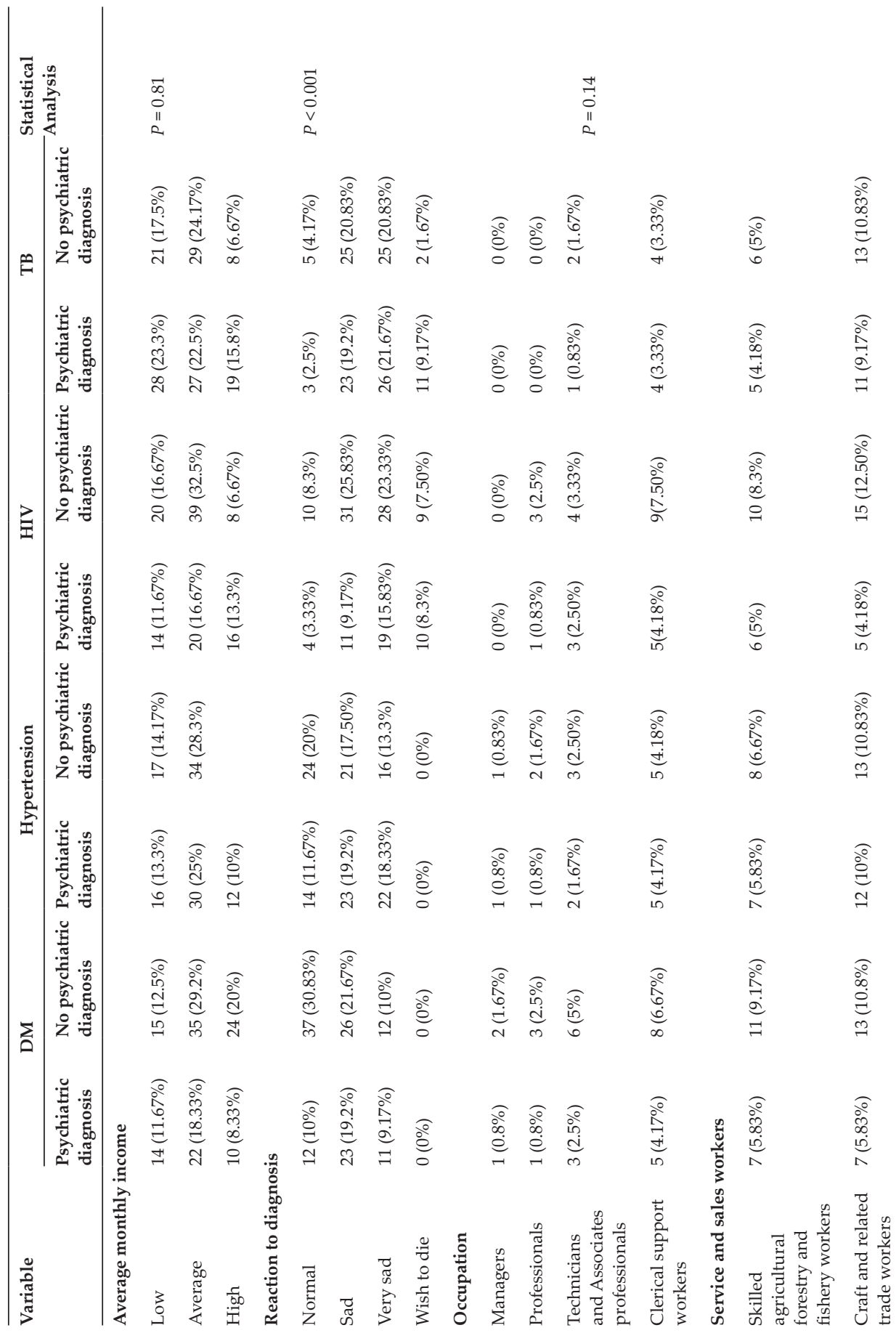




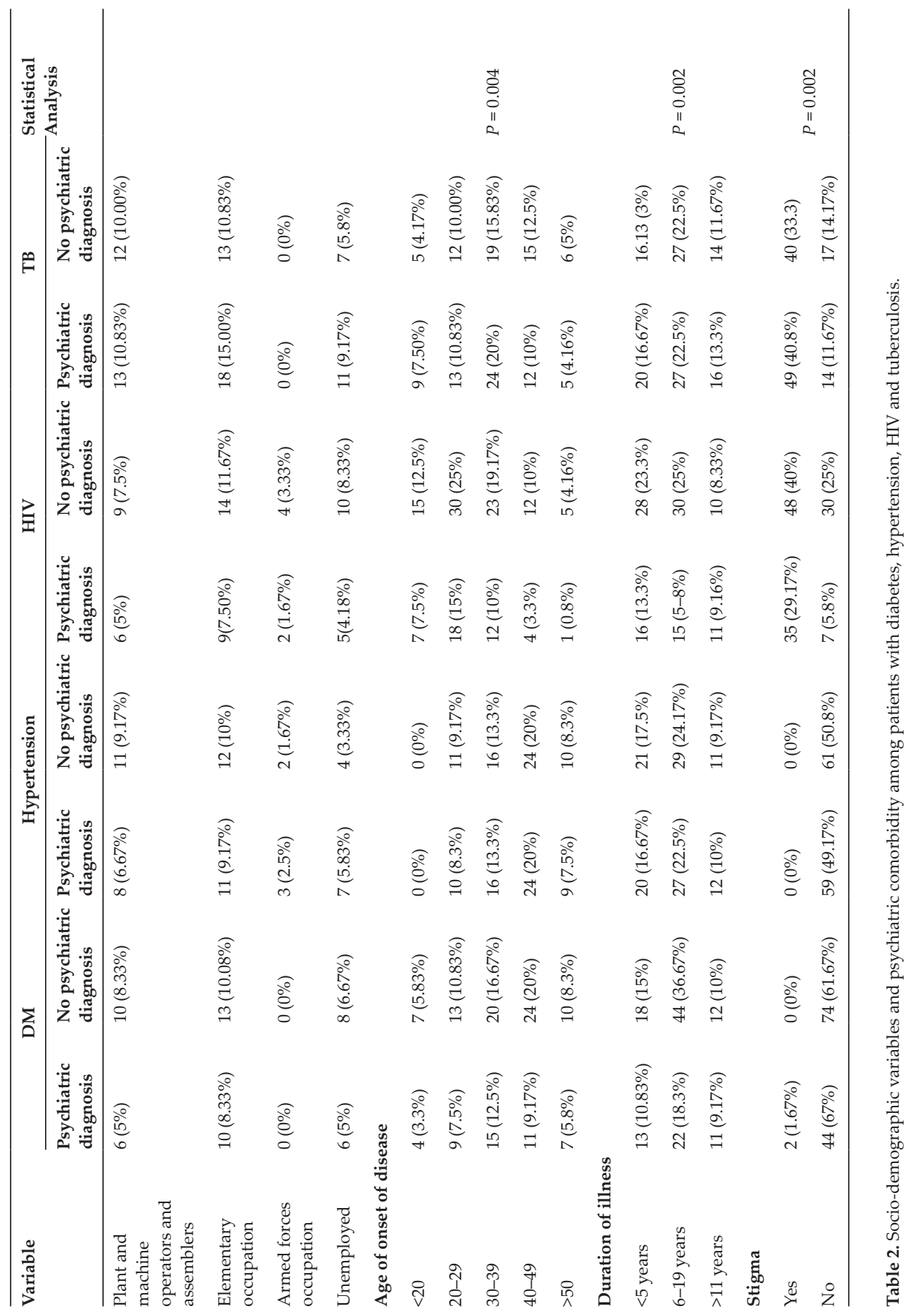




\begin{tabular}{|c|c|c|c|c|c|c|}
\hline \multirow{2}{*}{$\begin{array}{l}\text { Medical } \\
\text { condition }\end{array}$} & \multirow{2}{*}{$\begin{array}{l}\text { Status of } \\
\text { psychiatric } \\
\text { comorbidity }\end{array}$} & \multicolumn{5}{|c|}{ Domains of quality of life } \\
\hline & & $\begin{array}{l}\text { Domain } 1 \\
\text { (Physical) }\end{array}$ & $\begin{array}{l}\text { Domain } 2 \\
\text { (Psychological) }\end{array}$ & $\begin{array}{l}\text { Domain } \\
3 \text { (Social } \\
\text { Relationship) }\end{array}$ & $\begin{array}{l}\text { Domain } 4 \\
\text { Environment) }\end{array}$ & GHF \\
\hline \multirow[t]{3}{*}{$\mathrm{DM}$} & All patients & $51.97 \pm 14.77$ & $56.20 \pm 22.19$ & $57.51+26.13$ & $52.01+16.91$ & $48.34+22.44$ \\
\hline & $\begin{array}{l}\text { Psychiatric } \\
\text { comorbidity }\end{array}$ & $45.98+13.064$ & $56.60+24.914$ & $48.06+26.114$ & $44.95+14.831$ & $47.98+21.896$ \\
\hline & $\begin{array}{l}\text { No psychiatric } \\
\text { comorbidity }\end{array}$ & $60.46 \pm 12.788$ & $61.05+13.362$ & $66.80+21.378$ & $59.62+16.503$ & $51.91+23.319$ \\
\hline \multirow[t]{3}{*}{ HPT } & All patients & $50.97+14.671$ & $54.20+22.186$ & $54.51+26.13$ & $50.01+16.91$ & $49.34+22.44$ \\
\hline & $\begin{array}{l}\text { Psychiatric } \\
\text { comorbidity }\end{array}$ & $45.98 .+13.064$ & $56.60+24.914$ & $48.06+26.114$ & $44.95+14.831$ & $47.98+21.896$ \\
\hline & $\begin{array}{l}\text { No psychiatric } \\
\text { comorbidity }\end{array}$ & $60.46+12.788$ & $61.05+13.362$ & $66.80+21.378$ & $59.62+16.503$ & $51.91+23.319$ \\
\hline \multirow[t]{3}{*}{ HIV } & All patients & $60.71+15.57$ & $62.34+26.32$ & $61.57+25.04$ & $55.15+14.00$ & $65.81+21.84$ \\
\hline & $\begin{array}{l}\text { Psychiatric } \\
\text { comorbidity }\end{array}$ & $46.70+10.103$ & $48.67+15.016$ & $46.84+21.032$ & $50.33+10.456$ & $63.83+20.349$ \\
\hline & $\begin{array}{l}\text { No psychiatric } \\
\text { comorbidity }\end{array}$ & $66.36+13.698$ & $67.85+27.870$ & $57.09+14.888$ & $67.50+24.102$ & $66.61+22.418$ \\
\hline \multirow[t]{3}{*}{ ТВ } & All patients & $50.97+14.671$ & $54.20+22.186$ & $54.51+26.13$ & $50.01+16.91$ & $49.34+22.44$ \\
\hline & $\begin{array}{l}\text { Psychiatric } \\
\text { comorbidity }\end{array}$ & $45.98+13.064$ & $56.60+24.914$ & $48.06+26.114$ & $44.95+14.831$ & $47.98+21.896$ \\
\hline & $\begin{array}{l}\text { No psychiatric } \\
\text { comorbidity }\end{array}$ & $60.46+12.788$ & $61.05+13.362$ & $66.80+21.378$ & $59 . .62+16.503$ & $51.91+23.319$ \\
\hline $\begin{array}{l}\text { Statistical } \\
\text { analysis }\end{array}$ & & $P=0.001$ & $P=0.001$ & $P=0002$ & $P=0.004$ & $P=0.24$ \\
\hline
\end{tabular}

$\mathrm{DM}=$ diabetes mellitus, $\mathrm{HPT}=$ hypertension, $\mathrm{HIV}=$ human immunodeficiency virus, $\mathrm{TB}=$ tuberculosis, $\mathrm{GHF}=$ general health facet.

Table 3. Association of psychiatric comorbidity with quality of life among patients with diabetes mellitus, hypertension, HIV and tuberculosis.

\section{Discussion}

Young adults from 35 years and above predominated the diabetic mellitus, hypertension and the tuberculosis groups. This is in agreement with earlier studies [4, 14, 18, 19, 35, 97, 98]. Apart from the influence of genetic predisposition, diabetic mellitus and hypertension are largely diseases of lifestyles including unhealthy eating habits, alcohol intake and sedentary lifestyles, which would manifest most among adults $[4,14,18,19]$. Similarly, tuberculosis is an infective disease and exposure to it may be more in adults who work in health-care facilities, are mostly close care givers to already infected persons, and also in individuals whose immunity may have waned due to poor nutrition, alcohol use, stress and other emotional 
illnesses, most times occasioned by the medical illness, as well as other infective diseases. HIV had the most of youngest population with age group as young as 10-19 years taking $16 \%$, while the peak age was 30-39 years. This is in line with earlier finding that HIV is more prevalent among young persons [25].

The prevalence of essential hypertension was noted to be increasing with age and was about twice higher in the age groups 40-49 and 50-59 and above, compared to age group of 30-39, and about six times higher compared with age group 20-29. This result is consistent with earlier studies which reported that about 4.3 million Nigerians above the age of 15 years are classified as being hypertensive [15]. Furthermore, the prevalence has been said to be related to age, particularly in females, with a substantial increase occurring after the age of 50 [15]. Africans usually seek medical attention mostly when illness has presented with disabling symptoms, and in most cases late, in spite of awareness of the diagnosis [99-101]. This is particularly more so for essential hypertension and diabetes mellitus. Voluntary testing which is a key aspect of the HIV prevention and control program is yet to achieve $100 \%$ success rate.

A preponderance of females was observed among all disease conditions, especially PLWHIV and hypertension which recorded more proportions of females compared to diabetes and tuberculosis. HIV is equally well-known to be commoner among females. Several reasons have been postulated for this observation. Females, by reason of their reproductive anatomy, have larger surface area for the transmission of the virus. It has also been reported that the sperm contains heavy viral concentrations per/ml compared to vaginal fluid. Unfortunately, cultural factors further heighten this adversity among the female gender. Although essential hypertension is more common in males, females may have been over-represented in this study due to two reasons. First, African females tend to have lower blood pressure than males early in life with a reversal of the trend after the age $45-50$ years [15]. This may be due to hormonal changes associated with the preparation for or actual menopause occurring at this age, couple with the increasing family and domestic (stressors) responsibilities shouldered by females in this age group. Males predominated among those with psychiatric comorbidity in all medical conditions except among PLWHIV. The tendency and willingness for females to present early to care facility may equally translate to early understanding of the nature and extent of their illness, early reduction in symptomatology and early reduction of emotional burden, which may all impact better mental health, good quality of life and well-being.

Also from the study, it was found that more of each of the categories (married, separated and widowed) had more psychiatric comorbidity among the hypertensives and diabetes than their corresponding groups in PLWHIV and tuberculosis. A possible explanation could be that in hypertension and diabetes, marital difficulties, separation and even widowhood may serve as baseline psycho-social factors that may act either singly or in synergy with the medical stressor to cause psychiatric comorbidity. The presence of these psycho-social stressors alone can equally predispose to hypertension and diabetes due mainly to stress. In PLWHIV and tuberculosis, however, they are likely to influence the outcome of the disease, so there is more likelihood of marital difficulty, separation and even divorce in the chronic infective diseases, adding to the medical stressor. Thus, in hypertension and diabetes, they are both causal and effectual while in HIV and tuberculosis infections, they are more of effects. 
Most of the subjects in this study had attained various levels of formal education especially secondary and tertiary. Perhaps the influence of westernization and urbanization in Rivers State, Niger Delta and Nigeria might have played an important role. Furthermore, the cosmopolitan nature of Port Harcourt, domiciling majority of ethnic groups in Nigeria, with over $50 \%$ of Nigeria's oil and gas businesses, makes education a priority. A good number (39\%) of the subjects with hypertension and diabetes had tertiary education. The fact that they were educated may have increased their chances of employment and possibly ability to seek quality health care and timely too [102]. It is equally important to note that perhaps the older you become, and probably with more education, the more your socio-economic and family responsibilities, with their accompanying stressors. A number of studies have implicated environmental stressors as important aetiological factors in high blood pressure and diabetes mellitus, particularly in already genetically predisposed individuals [21-24]. Occupational environments in Nigeria had remained stressful due to lack of job security and poor wages, confronting countless demands from members of the family in a poverty ravaged economy such as ours. In all groups, the incidence of psychiatric comorbidity was lowest among those with tertiary education. Hence, education tended to have some protective influence on the psyche of patients [102]. Expectedly, those with higher level of education were more likely to secure better employment, earn better income and have better access to quality health care, hence better quality of life and well-being.

In this study, there was significantly reduced rate of stigma among patients with hypertension and diabetes mellitus. Expectedly, therefore, the negative effect of stigmatization was felt more among patients with the infective conditions. Several studies have reported high rate of stigmatization among PLWHIV and tuberculosis [28, 29, 46, 103]. Due to fear of stigmatization with its accompanying negative psychological impact on the individual [104], such as to experience a second psychological trauma, many people living with HIV rather choose to avoid disclosure of their seropositive status, to even close relative, while such concealment is difficult in tuberculosis because of the natural course and eventual symptomatology of the disease. They have learned to absorb their shock alone because of a possible rebound negative effects of disclosure.

Majority of the respondents reacted 'sadly' or 'very sadly' to the diagnosis of their medical conditions. Of particular note was among subjects with HIV and tuberculosis infections where those who reacted 'very sadly' and even with a 'wish to die' were significantly higher compared to subjects with essential hypertension and diabetes. Death wish is the forerunner of suicidal ideation that may ultimately end in suicide. Thus, it is not surprising that 4 and 2 cases of suicide attempt were seen among PLWHIV and tuberculosis, respectively. The possible explanation to this is the degree of stigma and social rejection usually associated with the chronic infective conditions, mainly born out of ignorance and socio-cultural factors [103, 104]. From the results, initial reaction to the diagnosis of chronic medical conditions seems to assume some importance in this study with regards to psychiatric comorbidity. Also of note here is that more people reacted very emotionally to diagnosis of communicable diseases than the non-communicable diseases. This is expected considering the level of stigma, discrimination, social rejection and isolation, need for adjustment, lowered self-esteem, fear of spreading the illness to others, helplessness brought about by incapacitation, associated with the former. Theses ultimately generate enormous psychological trauma, increase morbidity and mortality $[29,56,104]$. 
The study found a prevalence of psychiatric comorbidity of $43.75 \%$ in all. Tuberculosis had the highest prevalence of psychiatric comorbidity with 63 (52.5\%), followed by hypertension with 59 (49.17\%) and diabetes mellitus 46 (38.3\%), while HIV was the least with 42 (35\%). Although, previous studies found variable prevalence rates of 82.6 [105], 46 [106] and 5-30\% [107] for HIV, 72 [108] and 46-47.2\% [109] for tuberculosis, 35\% for hypertension [15] and $37-48 \%$ for diabetes $[36,37]$, the lower prevalence rates of psychiatric comorbidity found in some of the medical conditions in this study particularly for HIV could be a reflection of increased awareness, following concerted efforts and aggressive campaigns by both government and voluntary organizations, more access to existing medical care, articulated interventional measures by government, such as the anti-retroviral and anti-tuberculosis schemes, and sustained efforts aimed at reducing stigma and discrimination. Furthermore, variable rates reported by previous studies may be due to the setting as well as methodology of the various studies.

Depressive illness was the most common in all four medical conditions, followed by generalized anxiety disorder. In a total of 17 patients (6 among the HIV and 11 among the tuberculosis) had psychosis which occurred following commencement of anti-retroviral and anti-tuberculosis medications, respectively.

For HIV, depressive illness was ... and this figure is similar to the finding of Olisah of $14.2 \%$ in a study in Nigeria [110] and also consistent with several other studies which put the prevalence of depression (among PLWHIV) at 5-25 [111] and 10-40\% [112]. Females recorded higher percentage of depressive illness in all medical conditions, consistent with the male to female ratio of 1:2 in depression [110,111]. This might also be due to reasons earlier given for overall psychiatric disorders. Anxiety and depression are frequently and highly occurring mental disorders in patients with chronic medical diseases [110-112]. When depression and anxiety comorbid with chronic medical diseases, it leads to poor adherence to medication, which is an important barrier to global control of chronic disease particularly tuberculosis and HIV and increases the risk of morbidity and mortality [113-116].

The possible aetiological mechanisms of depression in all four illnesses have been explained from the biological (physical) as well as the psychological points of view. For HIV, the viral cells and even some opportunistic infections and ketoacidosis and glucose deposit in the cerebral cortex may either directly destroy the brain cells responsible for emotions in the limbic system or in both cases, cause direct affectation of the neurotransmitter system altering their release or uptake, and in effect causing depression. From the psychological point of view, the burden of the illness, the thought of almost life-time use of medications, fear of and uncertainty about the future, chronic sense of rejection and feeling of loss, possible loss of functional capability with reduced quality of life, associated stigma in the case of HIV, and chronic leg ulcer and possible amputation in cases of complicated diabetic foot ulcers, regimented lifestyle particularly food intake for diabetes and fear of impending death, are all depressogenic factors and may have had additive effects for depression. Several studies have also established similar lines of thought [113-116]. The threat to life and perceived loss or difficulty having a life partner may be responsible for the anxiety among the PLWHIV and tuberculosis. The predominant feeling of loss involves functional incapability, loss of job, 
relationship and even difficulty to secure a life partner. Truly, these are both depressogenic and anxiogenic. Another reason for the frequent comorbidity is that there are commonly shared risk factors for the development of a variety of psychiatric and medical disorders including smoking and low socio-economic status [117, 118].

Depression, generalized anxiety disorder, somatization, posttraumatic stress disorder (PTSD), acute stress disorder, panic disorder, adjustment disorder, substance abuse, sexual disfunction, psychosis and bipolar affective disorder are the most common stress-related conditions of chronic medical disorders in this study [45, 50, 119-121]. HIV and tuberculosis, with all the psycho-social difficulties including stigma and social isolation, and associated economic burden due to its chronic nature with very little hope of long-term survival, could be weighed as catastrophic to many sufferers. Chronic medical conditions are commonly associated with stressful conditions like loss of losses and unemployment, prolonged difficulties and people at war front. It has been found that stress, which potentially causes anxiety, also increases the level of cortisol which in turn causes increased deposition of arterosclerotic deposits in the intima of blood vessels. These deposits gradually narrow the lumen of the vessels. This in turn increases arterial pressure, resulting in hypertension. Excessive cortisol predisposes to diabetes mellitus.

Dependence on alcohol and other drugs could be the response to anxiety and depression as many of the sufferers may use them to self-medicate these disabling psychological symptoms and disorders [62-64]. There is a bidirectional relationship between substance abuse and chronic diseases, that is, substance abuse particularly alcohol can cause hypertension while hypertension, on the other hand, can precipitate substance abuse due to frustration [91-93]. However, the true relationship still remains difficult to establish in this study. People with chronic medical condition tend to abuse substance mainly to self-medicate their depression or to abate the many anxiety or anxiety-like symptoms that characterized hypertension, hence the use of propranolol and diazepam which have anxiolytic effects.

It is important to note that the viral cells alone or acting together with opportunistic infections, disseminating tuberculosis to the CNS or most substances of abuse, particularly alcohol, can directly impair or damage brain cells. Thus, these will synergistically hasten the deterioration of the health of the individual, thereby negatively affecting his/her psychological well-being and quality of life. Second, interactions between substances of abuse, particular alcohol, and anti-retroviral and anti-tuberculosis medications have also been associated with poor drug adherence, as well as reduced effectiveness of medications, which may result in unbearable side effects, often contributing to poor drug adherence.

Majority of the patients in all medical conditions fared well on most domain 65, 66, 76, 122-124]. The possible reasons being their focus on physical strength (e.g. evident physical health, absence of symptoms, ability to work around, available family support and a strong religious belief) than on their weaknesses (e.g. social discrimination, difficulty in having intimate relationships and reduced job opportunity). On domains 1 and 4, PLWHIV who had psychiatric comorbidity had better performance on quality of life, followed by hypertension, diabetes mellitus while tuberculosis had the least in similar domains. Furthermore, PLWHIV free of psychopathology also scored higher on GHF than similar group among the other three medical conditions. 
It is true that the stress, depression and lack of adequate social support which often may synergistically hasten the progression of HIV to AIDS, and by so doing, cause rapid deterioration in their psychological well-being and quality of life. However, in this study, it appeared that the combined effects of Government intervention programs and education for the general public as well as the supportive involvement by significant family members may have helped to increase the level of social support, reduced economic burden of care and associated stress which ultimately reduced the prevalence and severity of depression and other psychiatric disorders. This often results in improved quality of life. At present, more concern and care are given to PLWHIV, unlike diabetic mellitus, hypertensive and tuberculosis patients, from both governmental and non-governmental organizations, other social groups as well as the family.

Some authors have opined that quality of life will be poor in the developing countries like Nigeria where factors of finances, social relationships, health and personal safety are considered to be poor [124, 125]. Chronic medical conditions have high impact on the economy and with consequent low quality of life of individuals. The results in this study are consistent with many studies elsewhere [35, 125]. All domains of quality of life in those whose illness was complicated with psychiatric disorders among the medical conditions were affected, significantly worse in domains 1-4, compared to those without psychiatric comorbidity. This finding varied a little from previous studies where all domains of QOL except domain 4 (environment) and health satisfaction were affected by psychiatric comorbidity [125]. The result of this study is also consistent with the finding of Oliseh in his study done in Nigeria in which depression was the most prevalent psychiatric comorbidity, found that $63.6 \%$ subjects with depression had poor overall QOL while only $11.3 \%$ of subjects with no depressive disorder had poor overall quality of life and asserted that this could be representative, as depression has been identified as the most prevalent psychiatric illness in PLWHIV/AIDS [64].

In the presence of psychiatric comorbidity, the quality of life in PLWHIV and tuberculosis patients was significantly affected, particularly on the psychological and social domains compared with diabetes mellitus and hypertension. This suggests that the stigma and social rejection associated with the communicable disease may play a significant role in the development of psychological illness. This also implies that even though psychiatric comorbidity is equally common in the diabetes mellitus and hypertension and affecting quality of life generally, the presence of psychiatric comorbidity in PLWHIV and tuberculosis tended to have more severe negative impact on quality of life.

The presence of symptoms of tuberculosis, hypertension and diabetes mellitus alone appear to be more disabling than those in PLWHIV, bearing in mind that acute cases were excluded. Moderate to severe cases of diabetes mellitus, hypertension and tuberculosis cause more symptoms and they are more disabling. This may account for the better quality of life among PLWHIV on the physical domain and the lower quality of life scores on both the physical and environment domains among them compared with PLWHIV.

In this study, it was observed that socio-demographic and clinical characteristics of respondents in all medical conditions had some significant relationships with quality of life. Factors 
like increased age, marital status (married), later age of onset of illness, education, employment, average to high monthly income, shorter duration of illness, longer duration of treatment and emotional stability positively affected both psychiatric comorbidity and quality of life in all the groups. These results are consistent with several studies [124]. These suggested that a good number of psycho-social and clinical factors affected the outcome of the medical conditions. The implication of this is that these factors have to be addressed in the holistic management of these and indeed other chronic medical conditions.

The effect of gender was variable. Although, females were more affected in most of the psychiatric illnesses which is consistent with existing literature, this did not translate into lower quality of life for females on most domains of quality of life. This suggests that psychiatric comorbidity in females tended to have better prognosis compared with males. From the study, females performed better on the overall quality of life, domains $2-4$, while males fared better on health satisfaction and domain 1. This might be due to their better health-seeking behavior. Second, the obvious fact that most of the psychiatric disorders found in this study are usually associated with better prognosis in females, might have contributed to their better quality of life.

\section{Recommendations}

1. Based on the findings of this study, that chronic medical conditions carry the risk of psychiatric comorbidity with consequent affectation of quality of life and well-being, it becomes imperative that renewed efforts by Government, aimed at both primary and secondary prevention, be intensified for these chronic medical conditions.

2. That the intervention of Government in terms of increasing awareness campaign as well as free anti-retroviral and anti-tuberculosis scheme of the federal government for PLWHIV and tuberculosis should be sustained and further extended to non-communicable diseases.

3. Attention of clinicians should be drawn to diagnosing early psychiatric complications of chronic medical diseases and adequate management instituted or referrals made.

\section{Conclusion}

From the study, presence of psychiatric comorbidity and other psycho-social factors also influence the outcome of these medical conditions and to some extent significantly determined the psychological well-being and QOL. On account of the above, advocacy for a formal integration of functional Liaison-psychiatric practice has become imperative in the management of most chronic medical conditions for optimal benefits of patients and physicians, as early identification and prompt attention to the psychological components will, no doubt, go a long way in improving the clinical outcomes of the sufferers. 
Furthermore, efforts of both governmental and non-governmental organizations in the management of chronic health conditions, including communicable and non-communicable conditions should have clear objectives backed by legislation and not on ad hoc basis, as this would guarantee its sustenance.

\section{Author details}

Nkporbu A.K.

Address all correspondence to: nakpigi2008@yahoo.com

Department of Neuropsychiatry, University of Port Harcourt Teaching Hospital, Port Harcourt, Nigeria

\section{References}

[1] Centres for Disease Control and Prevention HIV/AIDS Surveillance Report. 2004;12 (No.1):1-42

[2] Kochi A. The global tuberculosis situation and the new control strategy of the World Health Organization. Tubercle. 1991;72(1):1-6

[3] Shaw JE, Sicree RA, Zimmet PZ. Global estimates of the prevalence of diabetes for 2010 and 2030. Diabetes Research and Clinical Practice. 2010;87(1):4-14

[4] Unachukwu CN, Agomoh DI, Alasia DD. Pattern of non-communicable diseases among medical admissions in Port Harcourt, Nig. Nig. Journal of Clinical Practice. 2008;11(1):14-17

[5] World Health Organization. Global Tuberculosis Control 2010. Geneva, Switzerland: World Health Organization; 2010. http://www.who.int/tb/publications/global_report/ en/index.html

[6] Aydin IO, Ulusahin A. Depression, anxiety comorbidity, and disability in tuberculosis and chronic obstructive pulmonary disease patients: applicability of GHQ-12. General Hospital Psychiatry. 2001;23(2):77-83

[7] Cook J, Grey D, Burke J, et al. Depressive symptoms and AIDS-related mortality among a multiside cohort of HIV-positive women. American Journal of Public Health. 2004;94:1 133-1140

[8] Carroll D, Phillips AC, Gale CR, Batty GD. Generalized anxiety and major depressive disorders, their comorbidity and hypertension in middle-aged men. Psychosomatic Medicine. 2010;72:16-19

[9] Gwatkin D, Guillot M, Heuveline P. The burden of disease among the global poor. Lancet, 2000;354:586-589 
[10] Murray CJ, Lopez AD. Mortality by cause for eight regions of the world. Global burden of disease. Lancet. 1997;349:1269-1276

[11] Rajeswari R, Balasubramanian R, Muniyandi M, Geetharamani S, Thresa X, Venkatesan P. Socio-economic impact of tuberculosis on patients and family in India. International Journal of Tuberculosis and Lung Disease. 1999;3(10):869-877

[12] Dye C, Scheele S, Dolin P, Pathania V, Raviglione MC. Global burden of tuberculosis: Estimated incidence, prevalence, and mortality by country. Journal of the American Medical Association. 1999;282(7):677-686

[13] Waisbord S. Behavioral Barriers in Tuberculosis Control: A Literature Review. Washington, DC, USA: The CHANGE Project/Academy for Educational Development; 2004

[14] Kearney PM, Whelton M, Renoids K, Muntner P, Whenton KP. Global burden of hypertension: Analysis of worldwide data. Lancet. 2005;365:217-223

[15] Erhun WO, Olayiwola, G, Agbani EO, Omotoso NS. Prevalence of hypertension in a University Community in South Western Nigeria. African Journal of Biomedical Research Ibadan Biomedical Communication Group. 2005;8:15-19

[16] Van de Sande MAB, Bailey R, Faal H, Banya WA, Dolin P, Nyan OA, Ceesay SM, Walraven GE, Johnson GJ, McAdamKP. Nationwide prevalence study of hypertension and related non-communicable diseases. Tropical Medicine \& International Health. 1997;2:1039-1048. CrossRefMedline

[17] Briganti EM, Shaw JE, Chadban SJ, Zimmet PZ, Welborn TA, McNeil JJ, Atkins RC. Untreated hypertension among Australian adults: The 1999-2000 Australian diabetes, obesity and lifestyle study. Medical Journal of Australia. 2003;179:135-139

[18] Adefuye BO, Adefuye PO, Oladepo TO, Familoni OB, Olurunga TO. Prevalence of hypertension and other cardiovascular risk factors in an African Urban, sub-urban religious community. Nigerian Medical Practitioner. 2009;55(1-2):4-8

[19] Wokoma FS, Alasia DD. Blood pressure pattern in Barako: A rural community in Rivers State, Nigeria. The Nigeria Journal. 2011;11:813

[20] Ota M., Issiki M. An Outbreak of tuberculosis in a long-term care unit of a mental hospital. Kekkaku. 2004;79(10):579-586

[21] Lifton RP, Gharavi AG, Geller DS. Molecular Mechanisms of Human Hypertension. ScienceDirect. 2001;104(4):545-556

[22] Wilson FH, Disse-Nieodme S, Choate KA, et al. Human hypertension caused by mutations in WNK kinases. Science. 2001;293(5532):1107-1112

[23] Pickering TG. Devereux RB, James GD, et al. Environmental influences on blood pressure and the role of job strain. Journal of Hypertension Supplement. 1999;341:120-124

[24] Bharat S, Aggleton P. Facing the challenge: household responses to AIDS in Mumbai, India. AIDS Care. 1999;11:31-44 
[25] Windle M. The trading of sex for money or drugs, sexually Transmitted Diseses (STDs) and HIV related risk behaviors among polysubstance use and alcoholic inpatients. Drug and Alcohol Dependence. 1997;49:33-38

[26] Susser E, Valencia E, Miller M, Tsai WY, Meyer-Bahlburg H, Conover S. Sexual behavior of homeless mentally ill men at risk for HIV. American Journal of Psychiatry. 1995;1552:583-587

[27] Bird ST, Bogart LM, Delahanty DL. Health-related correlates of perceived discrimination in HIV care. AIDS Patient Care STDs. 2004;18:19-26

[28] Courtwright A, Turner AN. Tuberculosis and stigmatization: pathways and interventions. Public Health Reports. 2010;125(supplement 4):34-42

[29] Johnson RT. HIV. In: Johnson A, editor. Viral Infections of the Nervous System. 2nd ed. PA. USA: Lippincott-Raven; 1998. pp. 287-231

[30] Center for Disease Control and Prevention. Prevention and treatment of tuberculosis patients infected with human immunodeficiency virus: Principles of therapy and revised recommendations. MMWR. Morbidity and Mortality Weekly Report. 1998;47(RR-20): $1-51$

[31] World Health Organization. Burden: Mortality, Morbidity and Risk Factors, Global Status Report on Non-communicable Diseases. 2010. Available from: http://www.who. int/nmh/publications/ncd_report_chapter1pdf [Accessed: 1 October 2012]

[32] Sulehri MA, Dogar IA, Sohail H, et al. Prevalence of depression among tuberculosis patients. Agricultural Produce Market Committee. 2010;4:133-137

[33] Issa BA, Yussuf AD, Kuranga SI. Depression comorbidity among patients with tuberculosis in a university teaching hospital outpatient clinic in Nigeria. Mental Health and Family Medicine. 2009;6:133-138

[34] Deribew A, Tesfaye M, Hailmichael Y, et al. Common mental disorders in TB/HIV co-infected patients in Ethiopia. BMC Infectious Diseases. 2010;10:201

[35] Chaudhry R, Mishra P, Mishra J, Parminder S, Mishra BP. Psychiatric morbidity among diabetic patients: a hospital-based study. Indian Journal of Psychiatry. 2011;19(1):47-49

[36] De Ornelas Maia AC, Braga Ade A, Brouwers A, Nardi AE, De Oliveira e Silva AC. Prevalence of psychiatric disorders in patients with diabetes types 1 and 2 . Comprehensive Psychiatry. 2012;53(8):1169-1173

[37] Campbell LC, Clauw DJ, Keefe FJ. Persistent pain and depression: a biopsychosocial perspective. Biological Psychiatry. 2003;54(3):399-409

[38] Jonas BS, Franks P, Ingram DD. Are symptoms of anxiety and depression risk factors for hypertension? Longitudinal evidence from the National Health and Nutrition Examination Survey I Epidemiologic Follow-up Study. Archives of Family Medicine. 1997;6:43-49

[39] Markovitz JH, Matthews KA, Kannel WB, Cobb JL, O’Agostino RB. Psychological predictors of hypertension in the Frarningham Study. Journal of the American Medical Association. 1993;270:2439- 2443 
[40] Engum A. The role of depression and anxiety in onset of diabetes in a large populationbased study. Journal of Psychosomatic Research. 2007;62(1):31-38

[41] Takahashi H. Sympathetic hyperactivity in hypertension (in Japanese). Nippon Rinsho. Japanese Journal of Clinical Medicine. 2008;66(8):1495-1502

[42] Katze S, Nevid JS. Risk factors associated with posttraumatic stress disorder symptomatology in HIV-infected women. AIDS Patients Care and STDs. 2005;19(2):110-120

[43] Olley BO, Zeier MD, Seedat S, Stein DJ. Posttraumatic stress disorder among recently diagnosed patients with HIV/AIDS in South Africa. AIDS Acre. 2005;17(5):550-557

[44] Peltzer K, Naidoo P, Matseke G, Louw J, McHunu G, Tutshana B. Prevalence of posttraumatic stress symptoms and associated factors in tuberculosis (TB), TB retreatment and/or TB-HIV co-infected primary public health-care patients in three districts in South Africa. Psychology Health \& Medicine. In press

[45] Jaggarajamma K, Ramachandran R, Charles N, Chandrasekaran V, Muniyandi M, Ganapathy S. Psycho-social dysfunction: Perceived and enacted stigma among tuberculosis patients registered under revised national tuberculosis control programme. The Indian Journal of Tuberculosis. 2008;55(4):179-187

[46] Guruprasad KG, Niranjan MR, Ashwin S. A study of association of depressive symptoms among the type 2 diabetic outpatients presenting to a tertiary care hospital. Indian Journal of Psychological Medicine. 2012;34:30-33

[47] Poongothai S, Anjana RM, Pradeepa R, Ganesan A, Umapathy N, Mohan V. Prevalence of depression in relation to glucose intolerance in urban south Indians: The Chennai Urban Rural Epidemiology Study (CURES-76). Diabetes Technology \& Therapeutics. 2010;12:989-994

[48] Prasad R, Garg R, Verma SK. Isoniazid- and ethambutol-induced psychosis. Annals of Thoracic Medicine. 2008;3(4):149-151

[49] Martin SJ, Bowden FJ. Ethambutol toxicity manifesting as acute onset psychosis. International Journal of STD and AIDS. 2007;18(4):287-288

[50] Kennedy NA, Oluwaseun A, Denis AA, Chukwuemeka SP. Cycloserine induced-psychosis in a 22-year old male pharmacy student: A case report. American Journal of Psychiatry and Neuroscience. 2016;1:124-126

[51] Rabkin JG, Ferrando S, Lin SH, Sewell M, McElhiney M. Psychological effects of HAART: A 2-year study. Psychosoatic Medicine. 2000;62:413-422

[52] Wells K, Golding J, Burman M. Psychiatric disordesr In a sample of the general population with and without chronic medical conditions. American Journal of Psychiatry. 1988;145:976-981

[53] Ellen SR, Judd FK, Mijch AM, Cockram A. Secondary mania in patients with HIV infection. Australian \& New Zealand Journal of Psychiatry. 1999;33:353-360 
[54] Venugopal D, Patil TB, Gupta D, Murl M, Kar N, Sharam PSVN. AIDS related mania. Indian Journal of Psychiatry. 2001;43:242-245

[55] Benatar SR. Prospects for global health: Lessons from tuberculosis. Thorax. 1995;50(5): 487-489

[56] Grange JM, Festenstein F. The human dimension of tuberculosis control. Tubercle and Lung Disease. 1993;74(4):219-222

[57] Lerman I, Lozano L, Villa AR, et al. Psychosocial factors associated with poor diabetes selfcare management in a specialized center in Mexico City. Biomedicine \& Pharmacotherapy. 2004;58:566-570

[58] Lin EH, Katon W, Von Korff M, et al. Relationship of depression and diabetes self-care, medication adherence, and preventive care. Diabetes Care. 2004;27:2154-2160

[59] Bruce DG, Davis WA, Davis TM. Longitudinal predictors of reduced mobility and physical disability in patients with type 2 diabetes: The Fremantle diabetes study. Diabetes Care. 2005;28:2441-2447. [PubMed]

[60] Watters JK, Estilio MJ, Clark GL, Lorvick, J. Syringe and needle exchange as HIV/AIDS prevention for injection drug users. Journal of the American Medical Association. 1994;271:115-120

[61] Baum N, Rafle C, Lal S, Sales S., Page J, Campa A. Alcohol use accelerates HIV disease progression. AIDS Research and Human Retroviruses. 2010;26:511-518

[62] Kresina T, Fexner C, Sinclair J, et al. Alcohol use and HIV pharmacotherapy. AIDS Research and Human Retroviruses. 2002;18:757-770

[63] Peltzer K, Louw J, Mchunu G, Naidoo P, Matseke G, Tutshana B. Hazardous and harmful alcohol use and associated factors in tuberculosis public primary care patients in South Africa. International Journal of Environmental Research and Public Health. 2012;9(9): 3245-3257

[64] Bergner M. Quality of life, health status, and clinical research. Concepts of Health-related quality of life. Medical Care. 1989;27(Suppl):S148-S156

[65] Levine S, Croog S. What constitutes quality of life? A conceptualization of the dimensions of life quality in healthy Population and patients with cardiovascular disease. In: Wenger N, Mattson ME, Furgerg CD, Elinson J, editors. Assessment of Quality of Life in Clinical Trials of Cardiovascular Therapies. New York: Le Jacq; 1998. pp. 46-58

[66] Robinson S, Young T, Roos L. Estimating the burden of disease. Comparing administrative data and self-reports. Medical Care. 1997;35(9):932-947

[67] Patrick DL, Erickson P, editors. Concepts of health-related quality of life. In: Health Status and Health Policy: Quality of Life in Health Care Evaluation and Resource Allocation. New York: Oxford University Press; 1993. pp. 76-112 
[68] Testa MA, Hollenberg Anderson RA, Williams GH. Assessment of quality of life by patient and spouse during antihypertensive therapy with atenolol and nifedipine gastrointestinal therapeutic system. American Journal of Hypertension. 1991;4:363-373

[69] Oliva J, Fernández-Bolaños A, Hidalgo A. Health-related quality of life in diabetic people with different vascular risk. BMC Public Health. 2012;12:812

[70] Ahari SS, Arshi S, Iranparvar M, Amani F, Siahpush H. The effects of type II diabetes on quality of life. Journal of Ardebil University of Medical Sciences. 2008;8(4):394-402

[71] Ahmadi A, Hasanzadeh J, Mediseh MR, Lashkari L: Factors affecting quality of life in patients with type 2 diabetes in Chaharmahal \& Bakhtiari province. Journal of North Khorasan University of Medical Sciences. 2011;3(1):7-13

[72] Borzou R, Salavati M, Safari M, Hadadinejad SH, Zandieh M, Torkman B: Quality of life in type II diabetic patients referred to Sina Hospital, Hamadan. Zahedan Journal of Research in Medical Sciences. 2010;13(4):43-46

[73] Haririan H, Moghadasian S, Aghajanlou A. Quality of life and its dimensions in diabetic patients referred to diabetes center of Tabriz medical university. Iranian Journal of Diabetes and Lipid Disorders. 2009;9(2):152-160

[74] Brown J, Capocci S, Smith C, Morris S, Abubakar I, Lipman M. Health status and quality of life in tuberculosis. International Journal of Infectious Diseases. 2015;32:68-75

[75] Rajeswari R, Muniyandi M, Balasubramanian R, Narayanan PR. Perceptions of tuberculosis patients about their physical, mental and social well-being: a field report from south India. Social Science \& Medicine. 2005;60(8):1845-1853. DOI: 10.1016/j. socscimed.2004.08.024

[76] Adeyeye OO, Ogunleye OO, Coker A, Kuyinu Y, Bamisile RT, Ekrikpo U, et al. Factors influencing quality of life and predictors of low quality of life scores in patients on treatment for pulmonary tuberculosis: A cross sectional study. Journal of Public Health in Africa. 2014;5(2). DOI: 10.4081/jphia.2014.366

[77] Balgude A, Sontakke S. Study of impact of antitubercular therapy on quality of life. Indian Journal of Medical Sciences. 2012;66(3-4):71-77

[78] Aggarwal AN. Health-related quality of life: A neglected aspect of pulmonary tuberculosis. Lung India. 2010;27(1):1-3

[79] Chamla D. The assessment of patients' health-related quality of life during tuberculosis treatment in Wuhan, China. International Journal of Tuberculosis and Lung Disease. 2004;8(9):1100-1106

[80] Marra CA, Marra F, Cox VC, Palepu A, Fitzgerald JM. Factors influencing quality of life in patients with active tuberculosis. Health and Quality of Life Outcomes. 2004;2:58. DOI: $10.1186 / 1477-7525-2-58$

[81] Marra CA, Marra F, Colley L, Moadebi S, Elwood RK, Fitzgerald JM. Health-related quality of life trajectories among adults with tuberculosis: Differences between latent and active infection. Chest. 2008;133(2):396-403 
[82] Louw J, Peltzer K, Naidoo P, Matseke G, McHunu G, Tutshana B. Quality of life among tuberculosis (TB), TB retreatment and/or TB-HIV co-infected primary public health care patients in three districts in South Africa. Health and Quality of Life Outcomes. 2012;10:77. DOI: 10.1186/1477-7525-10-77

[83] KatonWJ. Epidemiology and treatment of depression in patients with chronic medical illness. Dialogues in Clinical Neuroscience. 2011;13:7-23

[84] Katon W, Lin EH, Kroenke K. The association of depression and anxiety with medical symptom burden in patients with chronic medical illness. General Hospital Psychiatry. 2007;29:147-155

[85] Chandra PS, Deepthi V, Jairam KR, Thomas T. Relationship of Psychological morbidity and quality of life to illness-related disclosure among HIV-infected persons. Journal of Psychosomatic Research. 2003;54:199-203

[86] Ii W, Liu L, Purnte JG, Li Y, Jiang X, Jin S, Ma. H, Kong L, Ma L, He X, Ma S, Chen C. Hypertension and Health related quality of life: An epidemiological study in Patients attending hospital clinic in China. Journal of Hypertension. 2005;23(9):1667-1676

[87] Olusina AK, Ohaeri JU, Subjective quality of life of recently discharged Nigerian Psychiatric patients. Social Psychiatry and Psychiatric Epidemiology. 2003;38(12):707-704

[88] Ustun TB, Ayuso-Mateos JL, Chatterji S, et al. Global burden of co-morbid depression in adults with Type 1 diabetes; systematic literature review. Diabetic Medicine. 2006;23(4); $445-448$

[89] Black SA, Markides KS, Ray LA. Depression predicts increased incidence of adverse health outcomes in older Mexican Americans with type 2 diabetes. Diabetes Care. 2003;26:28222828

[90] Pierdomenico SD, Di Nicola M, Esposito AL, et al. Prognostic value of different indices of blood pressure variability in hypertensive patients. American Journal of Hypertension. 2009;22(8):842-847

[91] Crosby G, Stall R, Paul J, Barrett D. Substances use and HIV risk profile of gay/bisexual males who drop substance abuse treatment. AIDS Education and Prevention. 2000;12:38-48

[92] WHOQOL-HIV Group. Preliminary development of the World Health Organization's Quality of Life HIV instrument (WHOQOL-HIV): Analysis of pilot version. Social Science \& Medicine. 2003;57:1259-1275

[93] Hiyasu Z, Kabir M, Abubarkar IS, Babashani M, Zubair ZA. Compliance to antiretroviral therapy among AIDSs patients in Aminu Kano Teaching Hospital, Kano, Nigeria. Nigerian Journal of Medicine. 2005;14:290-295

[94] Adamson TA, and Sijuwola, OA. Ilewo-Orile. Nigerian Epidemiological Study: Psychiatric morbidity in a rural community using the 12-item GHO. Nigerian Journal of Psychiatry. 2001;1(5):315-321

[95] Peyrot M, Rubin RR. Levels and risks of depression and anxiety symptomatology among diabetic adults. Diabetes Care. 1997;20:585-590 
[96] Kaholokula JK, Haynes SN, Grandinetti A, Chang HK. Biological, psychosocial, and sociodemographic variables associated with depressive symptoms in persons with type 2 diabetes. Journal of Behavioral Medicine. 2003;26:435-458

[97] Owoaje EE, Rotimi CN, Kaufman JS, Tracy J, Cooper RS. Prevalence of adult diabetes in Ibadan, Nigeria. East African Medical Journal. 1997;74:299-302

[98] Ogunrin AO, Odiase FE, Ogunniyi A. Reaction time in patients with HIV/AIDS and correlation with CD4 count: A case-control study. Transactions of the Royal Society of Tropical Medicine and Hygiene. 2007;101(5):517-522

[99] Levy A, Laska F, Abelhauser A, Delfraissy JE, Goujard C, Bowe F, et al. Disclosure of HIV seropositivity. Journal of Clinical Psychology. 1999;55:1041-1049

[100] Dressler WW. Social and cultural influences in cardiovascular disease: A review transcultural. Psychiatric Research Review. 1984;21:1

[101] Taghidisi MH, Borhani M, Solhi M, Afkari ME, Hosseini F. The effect of an education program utilizing PRECEDE model on the quality of life in patients with type 2 diabetes. Health Education Journal. 2012;71(2):229-238

[102] Chandra PS, Deepthivarma S, Manjula V. Disclosure of HIV infection in South India: Patterns, reasons and reactions. AIDS Care. 2003;15:207-215

[103] Boardman J, Petrusthkin H, Ovuga E. Psychiatric disorders in HIV Positive Individuals in Urban Uganda. British Journal of Psychiatry. 2005;29:455-460

[104] Jacob KS, Eapen V, John JK. Psychiatric morbidity in HIV infected individuals. Indian Journal of Medical Research. 1991;93:62-66

[105] Johnson J, Williams J, Rabkin J, et al. Axis 1 psychiatric symptomatology associated with HIV infection and personality disorder. American Journal of Psychiatry. 1995;152:551-554

[106] Aamir S, AishaComorbid anxiety and depression among TB patients. Journal of College of Physicians and Surgeon Pakistan. 2010;20(10):703-704

[107] Lopez AG. Tuberculosis and the severely mentally ill. American Journal of Psychiatry. 1994;151(1):151-152

[108] Olisah VO, Biayewu O, Sheikh TL. Depression Underdiagnosis and the effects on quality of life in outpatients with HIV at a Nigerian University Teaching Hospital. African Journal of AIDS Research. 2011;10(3):247-254

[109] Morrison MF, Prtitto JM, Ten Hanc T, Grttes DR, Chiappini MS, Weber AL, et al. Depressive and anxiety disorders in women with HIV infection. American Journal of Psychiatry. 2002;159:789-796

[110] Chandra PS, Ravi V, Desai A. Anxiety and depression among HIV-infected heterosexuals- A report from India. Journal of Psychosomatic Research. 1998;45:401-409 
[111] Barllett J. Addressing the challenges of adherence. Journal of Acquired Immune Deficiency Syndromes. 2002;29(Suppl 1)

[112] Bagchi S, Ambe G, Sathiakumar N. Determinants of poor adherence to anti-tuberculosis treatment in Mumbai, India. International Journal of Preventive Medicine. 2010;1(4):223-232

[113] Manoharam E, John KR, Joseph A, Jacob KS. Psychiatric morbidity, patients' perspectives of illness and factors associated with poor medication compliance among the tuberculous in Vellore, south India. Indian Journal of Tuberculosis. 2001;48:77-80

[114] Lustman PJ, Anderson RJ, Freeedland KE, et al. Depression and poor glycemic control: A meta-analytic review of the literature. Diabetes Care. 2000;23:934-942

[115] Patel V. Mental health in low- and middle-income countries. British Medical Bulletin. 2007;81-82(1):81-96

[116] Slama K, Chiang CY, Enarson DA, et al. Tobacco and tuberculosis: a qualitative systematic review and meta-analysis. International Journal of Tuberculosis and Lung Disease. 2007;11(10):1049-1061

[117] Chandra PS, Ravi V. Somatization disorder among HIV seronegative men. Indian Journal of Psychiatry. 1994;37:41-42

[118] Nakimuli-Mpungu E, MusIsl S, Mpungu S, Katabira E. Clinical presentation of bipolar mania in HIV-positive patients. Uganda Psychosomatics. 2009;50:325-330

[119] Martinez A, Israleski D, Walker C. Posttraumatic stress disorders in women attending human immunodeficiency virus outpatient clinics. AIDS Patient Care STDS. 2002;16:283-289

[120] Liu C, Johnson 1, Ostrow D, Silvestre A, Visscher B, et al. Predictors of lower quality of life in the HAART era among HIV infected men. Journal of Acquired Immune Deficiency Syndromes. 2006;24(4):470-477

[121] Goldney RD, Phillips PJ, Fisher LJ, Wilson DH. Diabetes, depression, and quality of life-a population study. Diabetes Care. 2004;27:1066-1070

[122] Larsson D, Lager I, Nilsson PM. Socio-economic characteristics and quality of life in diabetes mellitus / relation to metabolic control. Scandinavian Journal of Public Health. 1999;27:101-105

[123] Okunoye OC, Asekomeh GE, Iyagba MA, Owuchekwa AC. Qualiti of life of people living with HIV/AIDS in Port Harcourt. The Nigerian Health Journal. 2014;14:8-12

[124] Nor K, Tlou S, Norr J. The threat of AIDS for women in developing countries. In: Cohen F, Durham JD, editors. Women Children and HIV. New York: Springer Publishing Co; 1993. p. 263

[125] Demi A, Bakeman R, Richard S, Linda M, Brenda S. Suicidal thoughts of women with HIV infection: Effect of stressors and moderating effects of family cohesion. Journal of Family Psychology. 1998;12:344-353 
